ISAHP 1999, Kobe, Japan, August 12-14, 1999

\title{
SELECTING SITES FOR COMMUNITY COLLEGES ACROSS THE KINGDOM OF SAUDI ARABIA: AN APPLICATION OF THE ANALYTIC HEIRARCHY PROCESS
}

\author{
Asma M. A. Bahurmoz \\ Assoc. Prof. of Operations Research \\ King Abdulaziz University, Jeddah, Saudi Arabia. \\ e-mail: bahurmoz@kaau.edu.sa
}

\section{EXTENDED ABSTRACT}

Saudi Arabia occupies 2,250,000 square kilometers. Its population is estimated to reach 21 million in 2000. It is growing fast at a rate of 3.5. As a result of prosperous economy and welfare state policy the number of enrollment in schools is increasing at even a higher rate. By year 2010 the number of graduates from secondary schools is expected to be 258 thousand compared to 94 thousand in 1997. Enrollment in universities is following at similar pace. Students over crowd the eight universities and their eight branches. Averages of $75 \%$ of secondary graduates have been admitted in the last few years. The rest had very few options in further education. With such rapid growth of student population the above admission rate cannot be kept. This problem is coupled with the problem of graduate unemployment. Such problem is hard to accept in an economy depending highly on foreign manpower. It can be explained partly by the mismatching of the universities supply and the economy's demands of skills.

Experts in higher education suggest the set up of community colleges across the kingdom in order to reduce the pressure on universities and-diversify the skills of graduates in order to meet job market demand. The spread of community cólleges over the kingdom can also help in developing remote areas which is a major goal in the kingdom development plans.

Even though the Saudi educational system has a variety of junior colleges and institutes. The society does not consider them favorably when selecting the type of higher education to their children. Community college with its open door to continue education at universities is expected to be a better alternative to higher education. Since the ministry of higher education accepted the concept it is essential to plan the setting up of these colleges. Location, size, type and the minimum number of such colleges must be decided within the goals set out in the development plans.

To select the best location for a community college among many alternatives, a decision-maker is faced by many conflicting criteria. Most of these criteria are of qualitative nature. The Analytic Hierarchy Process (AHP) is well suited where the criteria are qualitative and have a large subjective component, thus requiring judgments. It provides the capability to accommodate some of the behavioral and political factors that influence the decision on process. AHP blends well-defined qualitative factors into a unified, quantitative system of evaluation. It allows decision-makers to rank alternatives according to the importance of the criteria and the extent to which they are met by each alternative. In the educational sector, such subjective factors play a more important role in decision making than they do in other sectors. The AHP has been applied to a variety of decision areas, however, its application to educational planning is scant. This, surprisingly, is the case with most of OR techniques. Only few papers present the application of the AHP to decision-making in the area of education. As far as Saudi Arabia is concerned this is the first real life application of the AHP.

Having determined the focus, which is selecting the best set of towns to locate community colleges, a tentative hierarchy was developed based on the author experience. It contains the main factors that influence selecting a location. These factors are divided into a set of sub-criteria for each factor. In order to have expert evaluation the hierarchy was incorporated in a questionnaire and mailed to 40 individuals most of them are members of the Higher Council of Education in the Kingdom whose duty is educational policy making and planning. 
The questionnaire consists of four parts:

1- A set of objectives for starting a community college in a specific site are suggested and the respondent was asked to reorder them and amend them.

2- A set of factors and their sub-factors that a decision maker would consider in locating a community college. The respondent was asked to examine them and add or delete any of the stated factors or the sub-ones.

3- List ten cities and towns that the respondent thinks that they should have priority to have community colleges.

4- Finally it is explained that another questionnaire will follow and requested those who would like to participate to provide their names and contact address.

Twenty responded to the questionnaire (that is a response rate of 50\%) of whom ten showed interest in participating in the second stage of the research. A very good feed back was obtained. Forty-seven towns were cited. Their frequency was between 10 and 1 .

Upon examining the results the preliminary hierarchy has been modified to consist of:

1- Level 1: Focus: Select the best set of locations.

2- Level 2: Factors: Educational, Demographic, Social, Economic, Costs, and Infrastructure.

3- Level 3: Sub-factors: diversify educational opportunities, provide educational opportunities where it does not exist, relieve pressure on existing universities; population of the location, population of the surrounding area, secondary graduates of the location; family stability, local demand, local jobs for graduates; nationalizing the labor force, promoting the local economy, creating new jobs; capital costs, operating costs; accessibility or closeness of airport and highways, housing, schools and hospitals, public amenities, communication facilities.

4- Levels 4\&5: Intensities and alternatives

Considering the large number of alternatives, the rating model of the AHP is implemented. The subfactors where further divided into a level of intensities. Each sub-factor was rated in term of set intensities in order to distinguish the quality of each alternative for that criterion.

The respondents who showed interest in participating in the decision making process where considered as the group decision- makers. Due to the difficulty of having them in a one-day meeting another questionnaire was designed to get the judgements through the pair comparison of the factors and the subfactors. Only the minimum number of judgements were asked (Saaty, 1996). Eight out of ten responded. The geometric mean approach is used to combine the pairwise comparison Judgement matrices obtained from the evaluators. Data required for ratings the alternatives were collected from different government agencies. The software Expert Choice was used to perform all the calculations required by the rating model of the AHP.

To sharpen the results and get the consent of the group decision makers, the top nine alternatives were selected and paired comparisons on them was performed directly with respect to the criteria after deleting the intensities from the hierarchy.

The results obtained can be used in many ways to help decision makers. Upon estimating the cost of the college at each site they can optimize employing Integer Programming to the optimal set which is within the available resources. Another way is to decide on the minimum number of community colleges needed to cover the kingdom. Weights of the alternatives that resulted from the analysis can be looked upon as profit/cost. Then these weights can be incorporated into a set-covering problem.

This research should draw the attention of decision - makers and planners in the Kingdom to the help and benefits they can get from the application of operations research techniques to rationalize demand on resources and allocate them efficiently. 